\title{
A Family Interpersonal Communication Inventory: A Development From Rasch Analysis
}

\author{
Afdal $^{1(*)}$, Herman Nirwana $^{1}$, Alfina Sari ${ }^{1}$, Yuda Syahputra ${ }^{1}$ \\ Fakultas Ilmu Pendidikan, Universitas Negeri Padang, Indonesia \\ *Corresponding author.Email: afdal@konselor.org
}

\begin{abstract}
Many divorces occur because of the lack of good interpersonal communication within the family. Therefore, there needs to be a valid and reliable inventory to measure interpersonal communication in the family. The purpose of this study was to test the validity, item suitability, item difficulty levels, rank scale validation, the ability of the person answers and the ability of the items in communication skills in the family. The sample used in this study was 86 people (43 men, 43 women) who were going to get married and were taken by purposive random sampling. The analysis used is the Rasch model. The analysis done was Reliability; Validity instrument; Item Validity; and rating scale validity. The analysis shows that the overall scale developed is valid and reliable (person reliability is 0.94 and item reliability is valid and reliable (person reliability is 0.91 and item reliability is 0.92 ), the use of inventory in measuring interpersonal communication in families to prepare for marriage and prevention of divorce discussed further
\end{abstract}

\section{Keywords: Interpersonal Communication, Instrument}

\section{INTRODUCTION}

Manusia merupakan makhluk biologis yang memiliki hasrat untuk melangsungkan perkawinan dan mengembangkan keturunan sebagai generasi penerus bagi garis keturunannya(Sari, Taufik, \& Sano, 2017;Rossi, 2017; Mascie-Taylor \& Krzyżanowska, 2017;Paul, 2015;Hoad, 2018;Elder., Shanahan, \& Jennings, 2015). Di dalam Al-Qur'an telah dijelaskan bahwa Allah SWT menciptakan manusia hidup secara berpasang-pasangan (Laluddin, Manap, Shariff, Husni, Kusrin, Ibrahim, \& Manap, 2014; Muhamad, 2015)dari jenis kelamin laki-laki dan perempuan yang diikat oleh sebuah perkawinan (Bima, Mutimatun, \& Iksan, 2016), Zaenal, \& Ismail, 2016;Ruwan-Doruwa, 2015;Djubaedah, 2019; Hacke, 2017; Regan, 2016). Menurut Undang-Undang No. 1 Tahun 1974"Perkawinan ialah ikatan lahir batin antara seorang pria dan seorang wanita sebagai suami istri dengan tujuan membentuk keluarga (rumah tangga) yang bahagia dan kekal berdasarkan Ketuhanan Yang Maha Esa".

Para ahli juga setuju bahwasanya perkawinan merupakan ikatan lahir batin untuk mencapai kebahagiaan (Hanzah, 2017; Ulum, 2017; Sari, 2016; Wok \& Hashim, 2015; Uchida \& Oishi, 2016). Selain daripada itu perkawinan juga merupakan ikatan yang sah antara pria dan wanita secara agama dan negara(Tuapattinaya \& Hartati, 2014; Zuhri, 2014) dalam rangka mengawali kehidupan rumah tangga yang harmonis dan sejahtera(Alsos, Carter, \& Ljunggren, 2014). Berdasarkan pengertian perkawinan, maka dapat disimpulkan bahwa perkawinan merupakan suatu ikatan lahir dan batin antara seorang pria dan seorang wanita dengan tujuan untuk mencapai kebahagiaan serta mewujudkan keluarga harmonis dan bahagia.

Meskipun demikian masih banyak keluarga yang belum mampu menciptakan keluarga yang harmonis dan bahagia (Yigibalom, 2013; Tirtawinata, 2013) kondisi keluarga yang tidak harmonis dan bahagia bermula dari timbulnya konflik di dalam rumah tangga(Alawiyyah, 2017; Adawiyah, 2018; Sari, 2018; Brickell, 2014; Van Hearm\& Cohen, 2017). Konflik tersebut disebabkan tidak terjalinnya komunikasi yang baik serta tidak diperolehnya pengalaman berarti dalam kehidupan sehari-hari yang mampu mengembangkan kehidupan keluarga menjadi damai, aman, sejahtera, dan langgeng (Afdal, 2015; (Rofiah, 2018; Qamariah, 2017; Farkhanudin, 2017). Konflik yang terjadi ini tentunya akan berakibat pada perceraian(Gager, Yabiku, \& Linver, 2016; Joo Kim, Yamaguchi, Kim, \& Miyahara, 2015). Perceraian dapat diartikan dengan putusnya hubungan perkawinan, sehingga hubungan antara suami istri berakhir (Sari, 2016; Fatmawati, 2017; Huda, 2017). Perceraian juga merupakan putusnya hubungan suami istri yang telah sepakat untuk menjalankan kehidupan secara bersama dalam pernikahan. Disisi lain Hurlock, (1997) menyatakan bahwa perceraian merupakan kulminasi dan penyesuaian perkawinan yang buruk, dan diantara keduanya sudah tidak mampu lagi mencari cara penyelesaian masalah yang dialami. Jadi 
dapat disimpulkan bahwa perceraian merupakan putusnya hubungan antara pasangan suami istri yang sudah tidak mampu lagi mencari cara penyelesaian masalah yang dihadapi.

Berdasarkan fenomena yang ada, kasus perceraian semakin meningkat disetiap tahunnya. Perceraian di Indonesia sendiri dalam kurun waktu tiga tahun terakhir (2015-2018) kecenderungan perkara putusan (inkracht) perceraian di Pengadilan Agama seluruh Indonesia pada tahun 2015 tercatat sebanyak 394.246 perkara. Di Tahun 2016 tercatat sebanyak 403.070 perkara, pada tahun 2017 , tercatat sebanyak 415.848 perkara. Kecenderungan perkara perceraian yang diputus dalam 3 tahun terakhir kisaran 353.843 hingga 374.516 perkara. Sebanyak 419.268 pasangan bercerai sepanjang 2018 (Pengadilan Agama Padang, 2018). Sedangkan Sumatera Barat tercatat sebagai provinsi dengan angka perceraian tertinggi se Indonesia. Pada periode tahun 2017-2018 Pengadilan Agama Sumatera Barat mencatat telah terjadi kasus perceraian sebanyak 20.359 kasus, dengan jumlah kasus terbanyak berada di Kota Padang sedangkan jumlah kasus terendah berada di Maninjau (Pengadilan Agama Padang, 2018).

Lebih lanjut, jumlah pengajuan cerai yang masuk di Pengadilan Agama Kota Padang Sumatera Barat pada periode tahun 2017 sebanyak 1.823 kasus, diantaranya sebanyak 1.805 kasus sudah diputus oleh hakim. Dari jumlah tersebut, sebanyak 1.374 kasus merupakan perceraian yang berawal dari gugatan istri terhadap suami, sedangkan sebanyak 431 kasus merupakan cerai talak gugatan dari suami terhadap istri. Perceraian yang terjadi bermula dari ketidakharmonisan dalam keluarga (Luthfi, 2017), hal ini disebabkan oleh berbagai faktor, salah satunya adalah komunikasi interpersonal yang kurang baik(Muhammad, 2015).

Semestinya perceraian dapat dicegah atau diminimalisir dengan berbagai cara, salah satunya adalah dengan menciptakan komunikasi yang baik dan asertif dalam keluarga (Pangaribuan, 2016), sehingga antara pasangan suami istri dapat meresolusi konflik yang konstruktif (Karel, 2014). Selain daripada itu, komunikasi interpersonal yang baik dapat membangunkedekatandankeintimandenganpasangan (Karel, 2014; Muqorrobin, 2017; Paramita, \& Suarya, 2018), dengan begitu pasangan suami istri akan menjadi keluarga yang harmonis dan bahagia(Romas, 2017). Besar sumbangan efektif yang diberikan komunikasi interpersonal pasangan suami istri terhadap keharmonisan keluarga adalah $42,2 \%$ dan sisanya 57,8\% dipengaruhi oleh faktor-faktor lain (Dewi \& Sudhana, 2013). Jadi jelas terlihat bahwa komunikasi merupakan faktor penting bagi keberfungsian keluarga dalam menjadikan keluarga harmonisdan bahagia (Lestari, 2012), serta pasangan suami istri memiliki kepuasan dalam pernikahannya (Muslimah, 2014).

Komunikasi interpersonal yang baik antara pasangan suami istri dapat dibentuk oleh BP4 (Badan Penasihatan Pembinaan dan Pelestarian Perkawinan) di KUA kepada calon pengantin yang akan melakukan melangsungkan pernikahan. Pemberian BP4 dilakukan oleh ahli bidang bimbingan dan konseling (Utami, 2015; Prabawati, 2016; Rustandi, 2016). Melihat pentingnya komunikasi interpersonal dalam mewujudkan keluarga harmonis dan bahagia, kurangnya pemahaman akan pentingnya komunikasi interpersonal, serta pelayanan bimbingan dan konseling di KUA yang belum maksimal, sekiranya komunikasi interpersonal sangat perlu untuk ditingkatkan agar pasangan suami istri mampu menjalin komunikasi interpersonal dengan baik di dalam keluarga, dengan begitu perceraian dapat dicegah dan diminimalisir. Namun hingga saat ini tidak ada inventory yang valid untuk mengukur komunikasi interpersonal yang akan digunakan oleh calon pasangan suami istri. Oleh karenanya inventory komunikasi interpersonal ini sangat perlu untuk dikembangkan guna meningkatkan pemahaman komunikasi interpersonal calon pasangan suami istri dalam keluarga, hingga begitu kebahagiaan dan keharmonisan dapat dirasakan dalam rumah tangga.

\section{METHOD}

Penelitian ini merupakan penelitian pengembangan (research and development)(Shaner, 2019)khususnya instrumen komunikasi interpersonal yang dikembangkan dari teori DeVito. Instrumen digunakan untuk mengukur kemampuan komunikasi interpersonal dalam keluarga. Skala yang digunakan dalam inventory komunikasi interpersonal ini adalah skala model likert. Sampel yang diambil dalam penelitian ini sebanyak 86 orang (43 lakilaki, 43 perempuan) yang akan menikah diambil dengan menggunakan teknik purposive random sampling. Penelitian ini menggunakan analisis model rasch.

\section{RESULTS AND DISCUSSION}

\section{Results}

\section{a. Reliability}

Reliabilitas suatu instrument merujuk pada stabilitas suatu pengukuruan dan konsistensi dalam pengukuran. Untuk mendapatkan informasi mengenai reliabilitas person dan reliabilitas item dapat ditampilkan dalam ringkasan statistic. Hasil ringkasan statistic dijelaskan lebih lanjut pada Tabel 1 berikut.

\section{Tabel 1.Summary Statistics}

\section{Estimation}

\begin{tabular}{|c|c|c|}
\hline & Person & Item \\
\hline Reliability & .87 & .98 \\
\hline Separation index & 2.57 & 6.58 \\
\hline Mean Measure & -.23 & .00 \\
\hline Mean INFIT MNSQ & .99 & .98 \\
\hline Mean OUTFIT MNSQ & .98 & .98 \\
\hline Cronbach Alpha (KR-20) & & \\
\hline
\end{tabular}

Pada Tabel 1 memperlihatkan hasil reliabilitas person sebesar 0.87, artinya kualitas jawaban yang diberikan person bagus. Seiring dengan nilai separation index sebesar 2.57 dengan nilai $\mathrm{H}=3.76$ (dibulatkan 4), artinya kelompok person yang mengerjakan instrument ada 4 kelompok (tinggi, sedang, rendah, dan sangat rendah). Hasil tersebut didapatkan melalui formula strata, $\mathrm{H}=$ $[(4 *$ separation $)+1] / 3$ (Sumintono \& Widhiarso, 2015) 
Sementara skor reliabilitas item sebesar 0.98 , artinya kualitas item sangat bagus untuk mengungkap komunikasi interpersonal. Selanjutnya, nilai alpha Cronbach (KR-20) sebesar $89 \%$, artinya interaksi antara person dan item bagus sekali. Selanjutnya, nilai separation indekx item sebesar $6.58(\mathrm{H}=9.1)$. Dari hasil nilai separation item menunjukkan hasil strata yang sangat sangat bagus, di mana instrument dapat dikelompokkan menjadi 9 kelompok atau instrument dapat mengukur person dengan kemampuan mulai yang sangat tinggi sampai sangat rendah dapat diukur dengan instrument ini. Jadi, nilai reliability item berhubungan dengan nilai separation, kedua nilai tersebut saling mendukung untuk kualitas intrumen yang sangat bagus, karena nilai reliability item menunjukkan nilai yang sempurna sehingga separation juga memunculkan hasil yang bagus untuk mengukur dengan kemampuan apapun.

\section{b. Validity Konstruk}

Validitas konstruk menjelaskan seberapa baik pengukuran telah sesuai dengan ekspektasi teoritis (Sumintono, B., \& Widhiarso, 2015). Maksudnya adalah berbagai ukuran yang terdapat dalam berbagai konteks teoritis, kesemuanya harus menunjukkan hubungan dengan konsep lain yang bisa diprediksi dan diinterpretasi dalam konteks tersebut. Analisis validity konstruk menggunakan Principal Component Analysis (PCA) dari residual, yaitu mengukur sejauh mana keragaman dari instrument resiliensi mengukur apa yang seharusnya diukur. Analisis PCA menggunakan 2 parameter, pertama nilai total raw variance in observation (minimal 40\%) dan kedua nilai total raw unexplained variance (minimum 15\%) (Linacre, 2011; Sumintono \& Widhiarso, 2015). Lebih lanjut disampaikan pada Tabel 2 berikut.

Tabel 2. Standardized Residual Variance

\begin{tabular}{lcccc}
\hline & & Empirical & Modeled \\
\hline Total raw variance in & 78.5 & $\begin{array}{c}100.0 \\
\%\end{array}$ & $100.0 \%$ \\
observations & \multicolumn{4}{c}{$\%$} \\
Raw variance & 38.5 & 49.1 & & $47.4 \%$ \\
explained by measures & & $\%$ & & \\
Raw unexplained & 40.0 & 50.9 & 100.0 & $52.6 \%$ \\
variance (total) & & $\%$ & $\%$ & \\
Unexplned variance in & 6.0 & 7.7 & 15.1 & \\
1st contrast & & $\%$ & $\%$ & \\
Unexplned variance in & 3.4 & 4.3 & 8.5 & \\
2nd contrast & & $\%$ & $\%$ & \\
Unexplned variance in & 3.1 & 4.0 & 7.8 & \\
3rd contrast & & $\%$ & $\%$ & \\
Unexplned variance in & 2.3 & 3.0 & 5.8 & \\
4th contrast & & $\%$ & $\%$ & \\
Unexplned variance in & 2.0 & 2.5 & 5.0 & \\
5th contrast & & $\%$ & $\%$ & \\
\hline
\end{tabular}

Pada Tabel 2 di atas, terlihat hasil total raw variance sebesar $49.1 \%$ tidak jauh berbeda dengan nilai ekspektasinya $47.4 \%$. Hal ini menunjukkan bahwa konstruk pada instrument sangat baik artinya item-item sudah mewakili pengukuran untuk komunikasi interpersonal, serta persyaratan minimum unidimensional 40\% telah terpenuhi (Linacre, 2011). Sementara hasil unexplained variance semua ( 1 st s/d 5 th) di bawah $15 \%$ yang menunjukkan tingkat independensi item dalam instrument yang baik untuk pengukuran komunikasi interpersonal. Dengan demikian kondisi ini menyatakan bahwa persyaratan unidimensionalitas instrument terpenuhi untuk 40 item yang digunakan dalam instrument komunikasi interpersonal adalah valid secara konstruk.

\section{c. Validity Instrumen}

Validitas person dan itemmenggunakan variable mapsdapat menunjukkan sebaran abilitas siswa di sebelah kiri dan sebaran tingkat kesulitan item di sebelah kanan (Sumintono \& Widhiarso, 2015). Lebih lanjut disampaikan pada Gambar 1 berikut.

Pada gambar 1 di atas menunjukkan variable maps, sebelum dijelaskan satu persatu variable maps diketahui bahwa wright map sebelah kiri untuk melihat informasi dari person dan wright map sebelah kanan untuk melihat fungsi pengukuran dari item-item. Wright map sebelah kanan menunjukkan item-item yang diberi note " $M$ " dengan jumlah item 40, terlihat pada gambar M7 yang diberi tanda lingkaran merah menunjukkan melewati dua standar deviasi, untuk pengukuran social kondisi ini kurang baik. Namun, untuk pengukuran performace test kondisi ini sangat baik karena melihat kemampuan calon pasangan suami istri yang paling rendah, sehingga masih bisa dipertimbangkan untuk digunakan. Sementara pada beberapa item yang diberi lingkaran merah juga menunjukkan item-item yang terindikasi mengukur konstruk yang sama, sehingga perlu adanya perbaikan pernyataan untuk item tersebut. 
2

Person - MAP - Item

<more $>$ | $<$ rare $>$

1

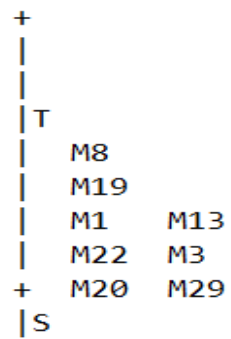

$\begin{array}{llll}P & P & T & M\end{array}$

\begin{tabular}{ll|ll}
$\mathrm{L} P \mathrm{P}$ & $\mathrm{M} 32$ & M38
\end{tabular}

$\begin{array}{llllllll}L & L & L & L & P & P & P & \text { | }\end{array}$

\begin{tabular}{lll|l}
$P$ & $P$ & $P$ & $M 9$
\end{tabular}

$\theta$

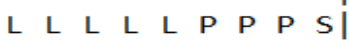

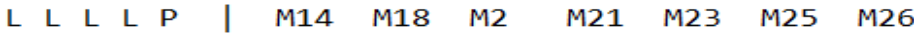

L L L P +M M10 M11 M40

\begin{tabular}{ll|lll}
$\mathrm{L}$ & $\mathrm{P}$ & $\mathrm{M}$ & $\mathrm{M}$
\end{tabular}

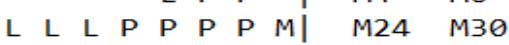

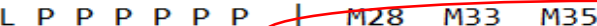

L L L L L L L L L L

\begin{tabular}{lllllll|llll}
\hline & $L$ & $L$ & $P$ & $P$ & $P$ & $P$ & M31 & M37
\end{tabular}

L L L L $\quad$ P $\quad$ S I $\quad M 17$

\begin{tabular}{lll|ll} 
L L L & S & M27
\end{tabular}

$-1$

$\mathrm{L} P+$

\begin{tabular}{l|lll}
$\mathrm{L}$ & $\mathrm{P}$ & $\mathrm{M} 15$ & M5
\end{tabular}

L T I

$P$

M16

I $\mathrm{T}$ M12

M7

$+$

$\langle$ less $>|\langle$ frequ $\rangle$

Gambar 1.Variable Maps

\section{d. Validasi item}

Dengan anilisis item measure dapat mengungkap fit statistic. Parameter yang digunakan untuk menunjukkan kesesuaian adalah outfit dari mean square dengan nilai kuadrat tengah 1.0 atau dengan rentang ideal $0.5>\mathrm{MNSQ}<1.5$ dan Z-standardized values dengan nilai kuadrat tengah 0.0 atau dengan rentang ideal-2.0>ZSTD< +2.0 (Bond \& Fox, 2015; Boone, Stever, \& Yale, 2014; Sumintono \& Widhiarso, 2015). Lebih lanjut disampaikan pada Tabel 3 berikut.

Tabel 3.Item Misfit

\begin{tabular}{ccc}
\hline \#Node Item & \multicolumn{2}{c}{ OUTFIT } \\
\cline { 2 - 3 } & MNSQ & ZSTD \\
\hline M16 & 1.44 & 2.3 \\
M17 & 1.42 & 2.8 \\
M9 & 1.42 & 2.4 \\
M24 & 1.31 & 2.2 \\
M23 & .52 & -3.9 \\
M10 & .71 & -2.2 \\
\hline
\end{tabular}

Pada Tabel 3, menunjukkan item misfit order berjumlah enam item. Dilihat dari nilai standardized values (ZSTD) sudah melewati rentang ideal ($2.0>$ ZSTD $<+2.0)$ sehingga item perlu dirubah pernyataannya untuk memenuhi kesesuaian. Perlu adanya revisi pernyataan untuk node M16, M17, M9, M24, M23, dan M10, karena untuk persyaratan ZSTD belum memenuhi atau melewati batas yang telah ditentukan.

\section{e. Keberfungsian item differensial (DIF)}

Instrument pengukuran maupun item dapat bersifat bias karena adanya perbedaan di mana item tertentu akan lebih memihak pada satu jenis tertentu saja (misalnya gender, agama, pekerjaan, pendidikan, latar belakang keluarga dll). Pada Tabel 4 berikut ditampilkan hasil analisis DIF, di mana bisa diketahui dengan nilai probabilitas di bawah (0.05) menunjukkan item yang terjangkit bias (Sumintono \& Widhiarso, 2015).

Tabel 4. Keberfungsian item differensial (DIF)

\begin{tabular}{cc}
\hline \#Node Item & PROB. \\
\hline M2 & .02 \\
M5 & .00 \\
M6 & .00 \\
M8 & .00 \\
M9 & .00 \\
M11 & .00 \\
M16 & .00 \\
M17 & .00 \\
M24 & .00 \\
M27 & .03 \\
M28 & .04 \\
\hline
\end{tabular}




\begin{tabular}{cc}
\hline M29 & .02 \\
M30 & .00 \\
\hline
\end{tabular}

Pada tabel 4 di atas terlihat 13 item yang terjangkit bias, pernyataan yang terdapat di dalam 13 item itu lebih memihak kepada salah satu responden, sehingga calon pasangan suami istri enggan memberikan jawaban (misalnya: pertanyaan yang lebih memihak pada wanita, sehingga laki-laki malu memberikan jawaban).

\section{Validasi Skala Peringkat}

Instrumen yang baik digunakan adalah instrumen yang tidak membingungkan responden dalam memilih jawaban yang disediakan oleh instrumen itu sendiri.Skala peringkat yang diberikan harus dipahami dengan baik oleh responden.Instrumen menggunakan 5 point Likert scale disampaikan pada gambar 2 berikut.

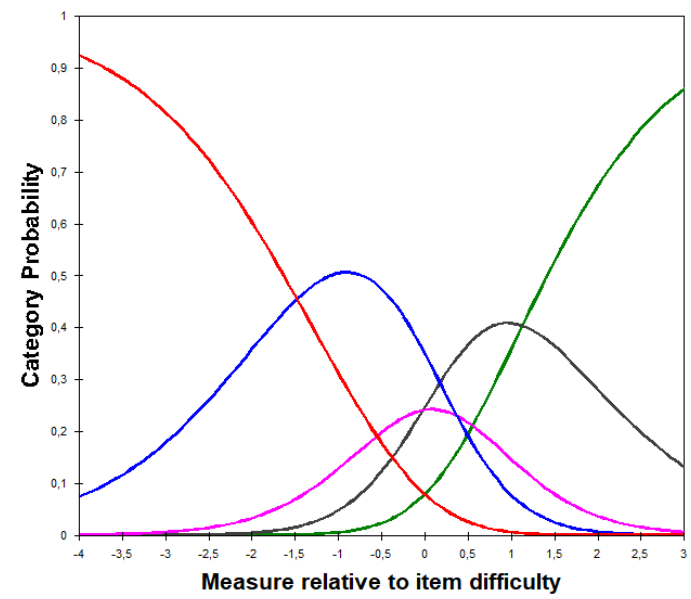

Gambar 2. Probability of Response

Pada gambar 2 di atas menunjukkan angka $1=$ selalu, $2=$ sering, $3=$ jarang, $4=$ kadang-kadang, dan $5=$ tidak pernah. Dari temuan tersebut menunjukkan bahwa empat pilihan yang diberikan sudah valid dalam instrument komunikasi interpersonal. Dari temuan di atas, dapat dinyatakan titik respon empat mudah dipahami pasangan suami istri, artinya responden tidak kebingungan dengan pilihan jawaban yang disediakan oleh instrument dan menciptakan hasil yang bagus. Namun, pada titik respon 3 pasangan kesulitan menentukan jawaban, sehingga perlu dihilangkan titik respon 3 pada instrument komunikasi interpersonal. Jadi instrument komunikasi interpersonal menggunakan skala likert 4 saja, yaitu: $1=$ selalu, $2=$ sering, $3=$ kadang-kadang, dan 4= tidak pernah.

\section{Discussion}

Komunikasi merupakan salah salah satu cara atau alat untuk berinteraksi antar individu yang menyentuh seluruh aspek kehidupan manusia yang tidak terlepas dari komunikasi setiap harinya(Storey, Zagalsky, Filho, Singer, \& German, 2017; Silverstone, 2017). Sebuah penelitian mengungkapkan bahwa $70 \%$ waktu manusia digunakan untuk berkomunikasi(BsY, 2012; Organisasi \& Furqon, 2003; Soemirat, 2014; Storey et al., 2017). Melalui komunikasi maka seseorang dapat meningkatkan interaksi sosial dengan orang lain(Bombari, Schmid Mast, Canadas, \& Bachmann, 2015; Guidelines, 2009; Smith, Thomas, \& Mcgarty, 2015). Komunikasi yang dilakukan dengan orang lain, disebut juga dengan komunikasi interpersonal(Li, 2017; Yulikhah, Bukhori, \& Murtadho, 2019).Komunikasi interpersonal merupakan komunikasi antara orang-orang secara tatap muka, yang memungkinkan setiap pesertanya menangkap reaksi orang lain secara langsung(Wellman \& Gulia, 2018; Wohn \& Birnholtz, 2015). Komunikasi interpersonal sangat potensial untuk menjalankan fungsi instrumental sebagai alat untuk mempengaruhi atau membujuk orang lain(Kamaruzzaman, 2016; Mambrasar, Pantouw, \& Marentek, 2017; Wahyuni, Ambara Jaya, \& Suarta, 2018; Wellman \& Gulia, 2018; Widiastuti, Koagouw, \& Kalangi, 2018; Wohn \& Birnholtz, 2015), karena setiap orang dapat menggunakan kelimat alat inderanya untuk mempertinggi daya bujuk pesan yang dikomunikasikan kepada komunikan. Sebagai komunikasi yang paling lengkap dan paling sempurna, komunikasi interpersonal berperan penting hingga kapanpun, selama manusia masih mempunyai emosi. Komunikasi interpersonal juga sangat penting dalam membangun hubungan (Minarsi, Nirwana, \& Syukur, 2017) salah satunya adalah hubungan dengan pasangan maupun keluarga.

Dalam kehidupan berkeluarga, komunikasi merupakan kebutuhan fundamental sebagai upaya membangun hubungan keluarga yang harmonis(Nawafilaty, 2016,). Melalui komunikasi yang baik antara suami dan istri akan memberikan manfaat dalam membangun kelangsungan hidup dalam keluarga sekaligus menjadi bagian yang tak terpisahkan dari kehidupan individu-individu dalam keluarga terutama dalam melakukan interaksi dengan lingkungan keluarga maupun di kehidupan bermasyarakat.

Komunikasi yang dijalin oleh seseorang dapat berupa komunikasi verbal maupun komunikasi nonverbal. Komunikasi verbal adalah komunikasi yang menggunakan simbol-simbol atau kata-kata, baik yang dikatakan secara oral, lisan, maupun tertulis(Aprilia, 2016; Damara, 2016). Sedangkan komunikasi nonverbal merupakan komunikasi yang menggunakan bahasa isyarat atau bahasa diam(Bailey, 2018, P. Yang, 2016; X. Yang, 2017). Komunikasi nonverbal adalah penciptaan dan pertukaran pesan yang dilakukan tidak menggunakan kata-kata seperti komunikasi yang menggunakan gerak tubuh, sikap tubuh, kontak mata, ekspresi wajah, kedekatan jarak dan sentuhan(Hidayat \& Hafiar, 2019; Indriani \& Prasanti, 2017).

Individu yang dapat menguasai kemampuan komunikasi nonverbal dan nonverbal dengan baik, maka akan dapat menunjang keberhasilan komunikasi interpersonal yang dilakukan, jika kedua aspek ini sejalan dan bersinergi maka akan menghasilkan komunikasi interpersonal yang berkualitas dan efektif. Oleh karenanya, sangat disarankan bagi pasangan calon pasangan suami istri untuk dapat menjalin komunikasi interpersonal baik secara verbal maupun nonverbal sebelum memasuki kehidupan dalam rumah tangga. Dengan penguasaan aspek komunikasi interpersonal yang baik, maka pasangan calon pengantin akan lebih mudah dalam menyikapi seluruh 
konflik yang nantinya muncul demi menciptakan dan menjaga keluarga agar tetap bahagia dan harmonis serta terhindar dari ancaman perceraian. Oleh karen itu, sekiranya instrument komunikasi interpersonal sangat perlu untuk dikembangkan dalam melihat pemahaman komunikasi interpersonal calon pasangan suami istri. Sehingga calon pasangan suami istri dapat terbantu dalam mewujudkan keluarga harmonis dan bahagia dalam kehidupan berumah tangga.

\section{CONCLUSION}

Berdasarkan hasil analisis dan pembahasan yang telah dilakukan, maka dapat diambil kesimpulan bahwa kualitas jawaban yang diberikan responden bagus dengan hasil reliabilitas respon sebesar 0.87. Seiring dengan kelompok person yang mengerjakan instrument ada 4 kelompok (tinggi, sedang, rendah, dan sangat rendah) dengan nilai separation index sebesar 2.57 dengan nilai $\mathrm{H}=3.76$ (dibulatkan 4). Kemudian, instrumen komunikasi interpersonal ini memiliki kualitas item yang sangat bagus untuk mengungkap komunikasi interpersonal dengan skor reliabilitas item sebesar 0.98. Untuk nilai alpha Cronbach (JR-20) sebesar $89 \%$, hal ini memiliki arti bahwa interaksi antara person dan item bagus sekali. Selanjutnya nilai separation indekx item sebesar $6.58(\mathrm{H}=91)$. Jadi nilai reliability item berhubungan dengan nilai separation, kedua nilai tersebut saling mendukung untuk kualitas intrumen yang sangat bagus, karena nilai reliability item menunjukkan nilai yang sempurna sehingga separation juga memunculkan hasil yang bagus untuk mengukur dengan kemampuan apapun.

Selanjutnya total raw variance pada validity konstruk sebesar $49.1 \%$ tidak jauh berbeda dengan nilai ekspektasinya yaitu $47.4 \%$. Ini berarti bahwa konstruk pada instrument sangat baik, artinya item-item sudah mewakili pengukuran untuk komunikasi interpersonal sebanyak 40 item instrument yang valid secara konstruk. Validity instrumen komunikasi interpersonal ini memiliki satu item yang melewati dua standar deviasi, dan sebanyak tujuh item yang terindikasi mengukur konstruk yang sama, sehingga perlu adanya perbaikan pernyataan untuk item tersebut.

Kemudian validasi item misfit order berjumlah enam item. Nilai standardized values (ZSTD) sudah melewati rentang ideal $(-2.0>Z S T D<+2.0)$ sehingga pernyataan item yangg perlu dirubah adalah node M16, M17, M9, M24, M23, dan M10. Sedangkan item yang terjangkit bias sebanya 13 item. Dimana di dalam 13 item tersebut lebih memihak kepada salah satu responden, sehingga calon pasangan suami istri enggan memmberikan jawaban. Pada hasil validasi skala peringkat, instrument komunikasi interpersonal ini menggunakan skala likert 4 saja, yaitu $1=$ selalu, $2=$ sering, $3=$ kadang-kadang, dan $4=$ tidak pernah.

\section{REFERENCES}

[1] Adawiyah, R. (2018). Kekerasan dalam rumah tangga (KDRT) dalam perspektif psikologi dan penanganannya menurut islam. Imtiyaz: Jurnal Ilmu Keislaman, 2(2), 144-158.
[2] Afdal, A. (2015). Pemanfaatan konseling keluarga eksperensial untuk penyelesaian kasus kekerasan dalam rumah tangga. Jurnal Educatio: Jurnal Pendidikan Indonesia, 1(1), 76-79.

[3] Alawiyyah, T. (2017). Konflik terselubung dalam keluarga: studi kasus perseteruan antara suami istri di Desa Prasung Tambak Kecamatan Buduran Kabupaten Sidoarjo. Doctoral dissertation, UIN Sunan Ampel Surabaya.

[4] Alsos, G. A., Carter, S., \& Ljunggren, E. (2014). Entrepreneurial families and households. The Routledge Companion to Entrepreneurship London: Routledge.

[5] Aprilia, V. (2016). Jom FISIP Volume 3 No. 2Oktober 20162 The meaning of symbolscultural communication in traditional marriage ceremony batak toba in Pekanbaru. 3(2), 1-15. Retrieved from

https://media.neliti.com/media/publications/33178 -ID-makna-simbolik-komunikasi-budaya-dalamupacara-adat-perkawinan-masyarakat-batak.pdf

[6] Bailey, B. (2018). The importance of nonverbal communication in business and how professors at the University of North Georgia train students on the subject. Retrieved from https://digitalcommons.northgeorgia.edu/honors_t heses/33?utm_source=digitalcommons.northgeorg ia.edu\%2Fhonors_theses\%2F33\&utm_medium $=\mathrm{P}$ DF\&utm_campaign=PDFCoverPages

[7] Bima, P, Y, R., Mutimatun, N. A., SH, M., \& Iksan, M, S. H. (2016). Kedudukan istri dan anak dalam pernikahan di bawah tangan menurut $U U$ No. 1 Tahun 1974 tentang perkawinan (studi putusan mahkamah konstitusi nomor 46/PUUVIII/2010. Tesis. Surakarta: Universitas Muhammadiyah.

[8] Bombari, D., Schmid Mast, M., Canadas, E., \& Bachmann, M. (2015). Studying social interactions through immersive virtual environment technology: virtues, pitfalls, and future challenges. Frontiers in Psychology, 6(June), $1-11$. https://doi.org/10.3389/fpsyg.2015.00869

[9] Brickell, K. (2014). 'Plates in a basket will rattle': Marital dissolution and home 'unmaking'in contemporary Cambodia. Geoforum, 5(1), 262 272.

[10]BsY, B. (2012). Pengembangan Kemandirian Belajar Berbasis Nilai Untuk Meningkatkan Komunikasi Matematik. Jurnal Pendidikan Matematika Dan IPA, 1(1), 11-22. https://doi.org/10.26418/jpmipa.v1i1.148

[11] Damara, D. (2016). Interaksi Sosial Pada Wong Mendo: Studi Di Desa Sidoharjo Kecamatan Jambon Kabupaten Ponorogo. Paradigma, 5(1)

[12] Dewi, N. R., \& Sudhana, H. (2013). Hubungan antara komunikasi interpersonal pasutri dengan 
keharmonisan dalam pernikahan. Junal Psikologi Udayana, 1(1), 22-31.

[13] Djubaedah, N. (2019). Child marriage and zina in Indonesian legislation in isamic law. Jurnal Hukum \& Pembangunan, 49(1), 210-231.

[14] Elder Jr, G. H., Shanahan, M. J., \& Jennings, J. A. (2015). Human development in time and place. Handbook of child psychology and developmental science.

[15]Farkhanudin, M. (2017). Pembinaan keluarga sakinah bagi keluarga muallaf: Studi kasus di Kementerian Agama Kota Malang. Doctoral dissertation, Universitas Islam Negeri Maulana Malik Ibrahim.

[16] Fatmawati, F. (2017). Kewenangan peradilan agama dalam memutus perkara perceraian akibat murtad. Jurnal Ilmiah Pendidikan Pancasila Dan Kewarganegaraan, 2(1), 26-33.

[17] Gager, C. T., Yabiku, S. T., \& Linver, M. R. (2016). Conflict or Divorce? Does Parental Conflict and/or Divorce Increase the Likelihood of Adult Children's Cohabiting and Marital Dissolution?. Marriage \& Family Review, 52(3), 243-261.

[18] Guidelines, U. (2009). BIROn - Birkbeck Institutional Research Online Mediating urban politics. 33, 246-249.

[19] Hacke, D. (2017). Women, sex and marriage in early modern Venice. Routledge.

[20] Hanzah, P. A. K. (2017). Doi Tekonggo dalam tradisi pernikahan masyarakat di Kabupaten Konawe Sulawesi Tenggara (tinjauan kesesuaian UU perkawinan No. 1 tahun 1974 dan hukum islam). Disertasi. Makasar: Universitas Islam Negeri Alauddin.

[21] Hidayat, D., \& Hafiar, H. (2019). Nilai-nilai budaya soméah pada perilaku komunikasi masyarakat Suku Sunda. Jurnal Kajian Komunikasi, $\quad 7(1), \quad 84$. https://doi.org/10.24198/jkk.v7i1.19595

[22] Hoad, N. (2018). Arrested development or the queerness of savages: resisting evolutionary narratives of difference. In Routledge Handbook of Queer Development Studies. Routledge.

[23] Huda, A. (2017). Peran Kerja Istri Sebagai Penyebab Perceraian. Usratuna: Jurnal Hukum Keluarga Islam, 1(1), 117-145.

[24] Hurlock, E, B. (1997). Psikologi perkembangan suatu pendekatan rentang kehidupan. Edisi kelima. Jakarta: Erlangga.

[25] Indriani, S. S., \& Prasanti, D. (2017). Penyuluhan Kompetensi Komunikasi Non Verbal Bagi Masyarakat di Desa Mekarmukti, Bandung Barat. Jurnal Pengabdian Pada Masyarakat, 2(1), 6274. https://doi.org/10.30653/002.201721.18

[26] Joo Kim, E., Yamaguchi, A., Kim, M. S., \& Miyahara, A. (2015). Effects of taking conflict personally on conflict management styles across cultures. Personality and Individual Differences, 72, 143-149.

[27] Kamaruzzaman, K. (2016). Analisis Keterampilan Komunikasi Interpersonal Siswa. Jurnal Konseling Gusjigang, 2(2), 202-210. https://doi.org/10.24176/jkg.v2i2.744

[28] Karel, R. S. (2014). Komunikasi antar pribadi pada pasangan suami istri beda negara (studi pada beberapa keluarga di kota Manado). Jurnal Acta Diurna, 3(4).

[29] Laluddin, H., Manap, N. A., Shariff, A. A. B. M., Husni, A. B. M., Kusrin, Z. M., Ibrahim, I. A., \& Manap, N. A. (2014). The contract of marriage and its purposes from Islamic perspective. Asian Social Science. 10(2), 139.

[30] Lestari, S. (2012). Psikologi keluarga: penanaman nilai dan penanganan konflik dalam keluarga. Jakarta: Kencana Prenada Media Group.

[31] Li, N. (2017). Analysis and strategy research on college students' interpersonal communication barriers. 96(Hsmet), 79-82. https://doi.org/10.2991/hsmet-17.2017.16

[32]Luthfi, M. (2017). Komunikasi interpersonal suami dan istri dalam mencegah perceraian di Ponorogo.2(1), 51-63. https://doi.org/10.21111/ettisal.v2i1.1413

[33] Mambrasar, Y., Pantouw, J. T., \& Marentek, E. A. (2017). "Peranan Komunikasi Interpersonal Dalam Menyelesaikan Studi S.1 di Universitas Sam Ratulangi Manado" (Studi Kualitatif Pada Mahasiswa Fispol Unsrat Asal Daerah Raja Ampat Papua Barat) oleh. Acta Diurna, VI(1).

[34] Mascie-Taylor, C. G. N., \& Krzyżanowska, M. (2017). Biological aspects of human migration and mobility. Annals of Human Biology, 44(5), $427-$ 440.

[35] Minarsi, M., Nirwana, H., \& Syukur, Y. (2017). Kontribusi Motivasi Menyelesaikan Masalah dan Komunikasi Interpersonal terhadap Strategi Pemecahan Masalah Siswa Sekolah Menengah. JPPI (Jurnal Penelitian Pendidikan Indonesia), 3(2), 1. https://doi.org/10.29210/02017113

[36] Muhamad, A. (2015). Appreciating The Immense Values of Biodiversity to Humanity: The Quranic Paradigm. QURANICA-International Journal of Quranic Research, 7(1), 17-36.

[37] Muhammad, F. (2015). Fenomena komunikasi interpersonal sebagai penyebab perceraian pada pasangan yang sudah bercerai di Kecamatan Koto Tangah Padang. Doctoral dissertation, Universitas Andalas.

[38] Muqorrobin, M. (2017). Model komunikasi sibernetika dalam konteks konseling perkawinan di Karangrejo Kecamatan Wonokromo Surabaya. Disertasi. Surabaya: Universitas Islam Negeri Sunan Ampel. 
[39] Muslimah, A. I. (2014). Kepuasan pernikahan ditinjau dari keterampilan komunikasi interpersonal. SOUL, 7(2), 14-22.

[40] Nawafilaty, T. (2016). Persepsi Terhadap Keharmonisan Keluarga, Self Disclosure dan Deliquency Remaja. Persona:Jurnal Psikologi Indonesia, 4(02). https://doi.org/10.30996/persona.v4i02.559

[41] Organisasi, H. K., \& Furqon, C. (2003). Hakikat Komunikasi Organisasi. Hakikat Komunikasi Organisasi, 2(15), 1-9.

[42] Pangaribuan, L. (2016). Kualitas komunikasi pasangan suami istri dalam menjaga keharmonisan perkawinan. Jurnal Simbolika: Research and Learning in Communication Study, 2(1). https://doi.org/10.31289/simbollika.v2i1.214

[43] Paramita, N. K. P., \& Suarya, L. M. K. S. (2018). Peran komunikasi interpersonal dan ekspresi emosi terhadap kepuasan perkawinan pada perempuan di usia dewasa madya. Jurnal Psikologi Udayana, 5(2), 241-253.

[44] Paul, R. A. (2015). Mixed messages: Cultural and genetic inheritance in the constitution of human society. University of Chicago Press.

[45] Pengadilan Agama Padang. (2018). Rekapitulasi laporan perkara yang diputus pada Pengadilan Agama se-wilayah Pengadilan Tinggi Agama Padang bulan Januari s/d Desember tahun 20172018. Padang.

[46] Prabawati, L. (2016). Bimbingan pra nikah sebagai upaya dalam mengembangkan keluarga sakinah: penelitian di BP-4 Kantor Urusan Agama Banjaran Jl. Ki Artasan Kecamatan Banjaran Kabupaten Bandung. Dissertation. Bandung: UIN Sunan Gunung Djati.

[47] Qamariah, L. (2017). Management konflik keluarga sebagai alat yang digunakan mediator di pengadilan agama klas IA Medan. Doctoral dissertation, Universitas Islam Negeri Sumatea Utara Medan.

[48] Regan, P. C. (2016). The mating game: A primer on love, sex, and marriage. Sage Publications.

[49] Rofiah, F. (2018). Human validation process model untuk meningkatkan keharmonisan keluarga di Desa Pagesangan Jambangan Surabaya. Doctoral dissertation, UIN Sunan Ampel Surabaya.

[50]Romas, M. Z. (2017). Kebahagiaan hubungan suami isteri ditinjau dari keterampilan komunikasi asertif. Jurnal Psikologi, 7(1).

[51]Rossi, A. S. (2017). Parenthood in transition: From lineage to child to self-orientation. In Parenting across the life span. Routledge.

[52] Rustandi, R. (2016). Peran bimbingan pranikah upaya membentuk keluarga sakinah: studi deskriptif di Kantor Urusan Agama Kecamatan Ujung Berung, Kota Bandung. Dissertation.
Bandung: UIN Sunan Gunung Djati.

[53] Ruwan-Doruwa, U. A. (2015). Rights of the wife under Islamic law. Gender and Behaviour, 13(1), 6488-6506.

[54] Sari, A., Taufik, T., \& Sano, A. (2017). Kondisi kehidupan rumah tangga pasangan sebelum bercerai dan faktor-faktor penyebab terjadinya perceraian. Jurnal Konseling Dan Pendidikan, 4(3), 41-51. https://doi.org/10.29210/113400.

[55] Sari, A. (2016). Konseling keluarga untuk mencegah perceraian. Jurnal Educatio: Jurnal Pendidikan Indonesia, 2(1). https://doi.org/10.29210/12016253.

[56] Sari, D. L. (2018). Penerapan model komunikasi transaksional antara suami dan istri dalam menghadapi konflik rumah tangga. Doctoral dissertation, University of Muhammadiyah Malang.

[57] Shaner, W. W. (2019). Farming systems research and development: Guidelines for developing countries. Routledge.

[58] Silverstone, R. (2017). Media, Technology and Everyday Life in Europe. Media, Technology and Everyday Life in Europe. https://doi.org/10.4324/9781315249384

[59] Smith, L. G. E., Thomas, E. F., \& Mcgarty, C (2015). "We Must Be the Change We Want to See in the World": Integrating Norms and Identities through Social Interaction. Political Psychology, $36(5)$, 543-557. https://doi.org/10.1111/pops.12180

[60] Soemirat, S. (2014). Falsafah dan Konsep-konsep Dasar Komunikasi Persuasif. Komunikasi Persuasif, 1-41. Retrieved from http://repository.ut.ac.id/4495/1/SKOM4326M1.pdf\%0Ahttp://www.pustaka.ut.ac.id/lib/2016/ 08/08/skom4326-komunikasi-persuasif/\#tab-id-3

[61] Storey, M. A., Zagalsky, A., Filho, F. F., Singer, L., \& German, D. M. (2017). How Social and Communication Channels Shape and Challenge a Participatory Culture in Software Development. IEEE Transactions on Software Engineering, 43(2), 185-204 https://doi.org/10.1109/TSE.2016.2584053

[62] Tirtawinata, C. M. (2013). Mengupayakan keluarga yang harmonis. Humaniora, 4(2), 11411151.

[63] Tuapattinaya, Y. I. F., \& Hartati, S. (2014). Pengambilan keputusan untuk menikah beda etnis: studi fenomenologis pada perempuan jawa. Jurnal Psikologi, 13(134-41).

[64] Uchida, Y., \& Oishi, S. (2016). The happiness of individuals and the collective. Japanese Psychological Research, 58(1), 125-141.

[65] Ulum, A. N. (2017). Istirdla' dalam pandangan hukum islam (analisis fatwa MUI nomor 28 tahum 2013 tentang seputar donor air susu ibu). Tesis. 
Lampung: Universitas Islam Negeri Raden Intan.

[66] US10007737.pdf. (n.d.).

[67] Utami, Y. S. (2015). Evaluasi strategi komunikasi konselor BP4 dalam mencegah perceraian. CHANNEL Jurnal Komunikasi, 3(2), 89-99. https://doi.org/10.12928/channel.v3i2.3276

[68] Van Hear, N., \& Cohen, R. (2017). Diasporas and conflict: distance, contiguity and spheres of engagement. Oxford Development Studies, 45(5), 171-184.

[69] Wahyuni, L. M., Ambara Jaya, I. M. S., \& Suarta, I. M. (2018). Keterampilan Komunikasi Yang Dibutuhkan Pasar Kerja Bidang Akuntansi: Studi Iklan Lowongan Kerja. Jurnal Bisnis Dan Kewirausahaan, 14(3), 142. https://doi.org/10.31940/jbk.v14i3.1096

[70] Wellman, B., \& Gulia, M. (2018). Net-surfers don't ride alone: Virtual communities as communities. Networks in the Global Village: Life in Contemporary Communities, 331-366. https://doi.org/10.4324/9780429498718

[71] Widiastuti, H., Koagouw, F. V. I. ., \& Kalangi, J. S. (2018). Teknik wawancara dalam menggali informasi pada program. Jurnal Acta Diurna, 7. Retrieved from https://ejournal.unsrat.ac.id/index.php/actadiurna/a rticle/view/19564

[72] Wohn, D. Y., \& Birnholtz, J. (2015). From ambient to adaptation: Interpersonal attention management among young adults. MobileHCI 2015 - Proceedings of the 17th International Conference on Human-Computer Interaction with Mobile Devices and Services, 26-35. https://doi.org/10.1145/2785830.2785865

[73] Wok, S., \& Hashim, J. (2015). The moderating effect of employee relations on networking towards workplace happiness among married women in Malaysia. Procedia-Social and Behavioral Sciences 211, 306-312.

[74] Yang, P. (2016). Intercultural nonverbal communication competence as intercultural responsiveness in the second language learning classroom. Intercultural Responsiveness in the Second Language Learning Classroom, (July), 127-147. https://doi.org/10.4018/978-1-52252069-6. ch008

[75] Yang, X. (2017). The Use of Body Language in English Teaching. Theory and Practice in Language $\quad$ Studies, 7(12), 1333. https://doi.org/10.17507/tpls.0712.23

[76] Yigibalom, L. (2013). Peranan interaksi anggota keluarga dalam upaya mempertahankan harmonisasi kehidupan keluarga di Desa Kumuluk Kecamatan Tiom Kabupaten Lanny Jaya. Jurnal Acta Diurna, 4(2).

[77] Yulikhah, S., Bukhori, B., \& Murtadho, A. (2019). Self concept, self efficacy, and interpersonal communication effectiveness of student. 4(1), 6576.

[78]Zaenal, M., \& Ismail, A. G. (2016). Slavery-A mere'commodity'or a human dignity: Classical view and solution. available at SSRN 2715265.

[79]Zuhri, S. (2014). Sanksi Pidana bagi Pelaku Nikah Siri dalam Perspektif Hukum Islam. 48(2), 363387. 